\title{
Cultural Challenges in Developing E-Learning Content
}

\author{
$\underline{\text { doi:10.3991/ijet.v6il.1467 }}$ \\ M. A. Azer, A.M. El-Sherbini \\ National Telecommunication Institute, Cairo, Egypt
}

\begin{abstract}
Education is an important component of any nation's development process. Society has been credited with creating technology, but technology is simultaneously creating society. One of the key benefits of such technology creation includes learning and curriculum development, which is otherwise referred to as e-leaning, and more appropriately referred to as global e-learning. Global e-learning raises some implications, which include communication, culture, and technology, that must be addressed before successful implementation and outcome can occur. In this paper, we discuss cultural related issues such as culture influence on e-learning and the dimensions of cultural variability. In addition, we present the main challenges to provide elearning opportunities. Finally, a case study for facing the cultural challenges is presented; this will be followed by concluding remarks at the end of this paper.
\end{abstract}

Index Terms-E-learning, cultural challenges, language barriers, technology.

\section{INTRODUCTION}

Learning is a lifelong process of skill and knowledge acquisition. It is critical in an era of rapidly increasing global innovation. The chief economic priority for developed countries is to raise the productivity of knowledge; the country that does this first will dominate the twentyfirst century economically. The educational system of today needs to impart to all learners three new foundational skills in order to make learning a relevant and lifelong process. These skills are: How to find information? How to determine if what is found is relevant to the task at hand? And how to determine if the relevant information is accurate? E-Learning seems the perfect answer to today's business needs, especially for large global businesses that have to train and retrain people constantly across national boundaries. As the Internet goes global so does e-learning [1]. E-learning supports the world-wide trend of offering online joint courses over the Internet, which includes institutes in different countries who employ roaming staff and who target mobile students [2]. However, as most elearning courses are designed in Western cultures, people specialized in educational programs have expressed concerns because targeted learners may experience inequitable learning outcomes if they are expected to use educational ICTs produced in another culture or country.

One of the important NTI objectives is to provide a high quality and an advanced postgraduate education in the field of telecommunications and information technology, to meet the demand for professional engineers in this field. The motivation for the establishment of an elearning center in NTI is to introduce the e-learning con- cepts in our life with all its benefits. The challenge is not to use new technologies to recreate traditional systems, but rather to create a new learning environment accommodating the learning needs of different cultures in order to promote equitable learning outcomes for targeted students, and to promote education and technological literacy that improve socio-economic opportunities in African and Arab countries. The remaining of this paper is organized as follows. In section II, cultural issues related to elearning are discussed; section III presents the cultural challenges facing developing countries in e-learning. Section IV is a case study for assessing and facing cultural challenges. Finally in section $\mathrm{V}$ conclusions and future work are presented.

\section{Cultural Issues}

In this section, we discuss some cultural issues that are e-learning related. Section A presents the problem statement and the factors that can affect cultural disparities. Section B explains the cultural influence on e-learning. Dimensions of cultural variability are presented in section C.

\section{A. Problem Statement}

The technology is there and so is the knowledge; but it's not working well. Although most developing countries are increasing their use of e-learning, growing evidence shows that the learners are not happy. There are many reasons for this apparent lack of enthusiasm: poor technology infrastructures in some regions; lack of design expertise; fear of technology on the part of users, and so on. But there's one readily identifiable cause that seems to go ignored: lack of cultural adaptation [3]. In [4], it was mentioned that in the year 2009 there were still many of the e-learning platforms that are not student driven but still deliver the same content for all the students. In essence, users of e-learning often ignore cultural implications and insights that employees or customers have in controlling how they learn and the learning process as a whole. Specifically, consumers of e-learning (e.g., purchasers, instructors, students, and end-users) are expected to work with curriculum designed in and for another culture [5].

Several factors [6] can generate or exacerbate these cultural disparities:

- The environments into which ICTs are introduced

- The types of technology used

- The content, philosophy and format of educational ICTs

- The characteristics of the learners themselves 
Providers of e-learning should be more aware of the cultural challenges and opportunities faced when designing and offering e-learning to learners in other cultures or countries and to explore various solutions.

\section{B. Cultural Influence}

As it is mentioned in [3], cultural difference has been deeply researched. The Dutch anthropologist Geert Hofstede defines culture as consisting of patterns of "thinking, feeling, and potential acting" that all people carry within themselves, and which he terms "mental programs." The source of these programs lies within the social environments where people grew up and collected their life experiences. Culture affects who we are, how we think, how we behave, and how we respond to our environment. Above all, it determines how we learn [3]. On a practical level, any professional trainer who has worked in different cultures will say that, to be effective, one needs an understanding of each individual culture. For example, open-ended, participative workshops don't work as well in cultures such as Japan and Holland where people feel most threatened by uncertain or unknown factors. Motivational techniques that work well in individualistic cultures (like the US), are guaranteed to alienate collective cultures (like India). Group assessment techniques that work well in cultures such as the UK and Sweden could be disastrous where learners expect to be strongly directed, such as Greece and Italy[3].

\section{Dimensions of Cultural Variability}

According to [5], one useful model in exploring cultural differences includes Hofstede's dimensions of cultural variability [7]. The four dimensions of cultural variability are: Power distance, uncertainty avoidance, individualism, and masculinity. These four categories result from data collected from fifty countries and three world regions. A brief description of the four dimensions includes the following:

Power distance is "the extent to which the less powerful members of institutions and organizations accept that power is distributed unequally" [8].

Uncertainty avoidance describes "the extent to which people feel threatened by ambiguous situations and have created beliefs and institutions that try to avoid these" [8 ].

Individualism-collectivism acknowledges the fact that in individualistic cultures, "people are supposed to look after themselves and their family only," while in collectivistic cultures, "people belong to in-groups or collectivities which are supposed to look after them in exchange for loyalty" [8].

Masculinity-Femininity Masculinity refers to cultures "in which dominant values in society are success, money and things," while femininity refers to cultures "in which dominant values are caring for others and quality of life" [8].

One of the challenges to dimensions of cultural variability is that comparisons are "relative" and "restricted" to two cultures or regions. Notwithstanding, these dimensions can still serve as a starting point for educational providers in global e-learning contexts. It is noted that cultural drivers of people play a significant role in learning, while representing the foundation for which global elearning platforms must be based [9].

\section{Cultural Challenges}

This section focuses on cultural challenges that face elearning. In section A, language is presented as being one of the barriers to access learning outcomes, whereas in section $\mathrm{B}$ we focus on technology as one of the e-learning challenges. Section $C$ illustrates the challenge of learning environment and the choice of media.

\section{A. Language}

One of the most obvious barriers to equitable learning outcomes when using educational ICTs are languages. According to [5] non- English speaking individuals may feel that technology has nothing to offer them since they cannot understand the content. Even in situations where people speak or understand English, its use is limited to certain contexts such as e-mail and entertainment. For instance, it is not uncommon for people in other cultures to restrict their English usage to work, school, or formal business settings, and use the local language for most of their daily communication encounters. Furthermore, scholars acknowledged that learning a second language in school is quite different from simply learning a foreign language itself. Moreover, as much as $36 \%$ of online users indicated that they would prefer a language that differs from English [9].

In a study of the global e-learning program offered by Cisco in the English language, students who use English as a second language indicated that they prefer their instructors to first overview the contents of the chapter before readings were assigned. In [5] it was mentioned that in a global e-learning curriculum, it may also help to note that even when curriculum is made available in languages other than English, there are differences within languages. For example, in the Cisco scenario mentioned above, French and Spanish versions of its e-learning course were provided. Unfortunately, the French version was the Canadian French, and the Spanish version was the South American Spanish, both of which differ from their European versions, thus creating problems for students from France and Spain, and necessitating the need to provide contents and services in localized language. In relation to the difficulty in language, it is suggested that the potential for information overload exists because non-native speakers read at slower speed than native speakers read [5]. Unfortunately, language barriers often result in national or cultural pride, which further put U.S. companies at a disadvantage in competing with homegrown developers and content providers. However, foreign language acquisition should never be considered as a substitute for making elearning contents available in local cultures' languages [5].

\section{B. Technology}

There are challenges with the frequency of technology use and the lack of comprehension of basic commands and protocols related to technology. Furthermore, due to lack of adequate infrastructure and failure to transfer technology, most organizations subcontract their e-learning needs to third party vendors. Some employees may have to travel several miles to access required e-learning curriculum, which does not bode well in motivating potential users to adopt the technology. The lack of technological infrastructure could derail any e-learning program regardless of how lofty its goal might be. In addition to how different cultures use or react to different technology me- 
dia, certain infrastructure, such as high speed Internet access, are simply not commonplace elsewhere around the globe [5].

\section{Learning Environment and the Choice of Media}

Perhaps one of the greatest struggles in e-learning across cultural contexts that one needs to be prepared for is the need to cultivate learning in a cultural environment, with the provision of a stronger blend of the familiar social environment and the virtual technology environment. In order to do this, the physical world of learners needs to coincide with the tools, signs, and symbols of the elearning world. To this end, it is suggested that simple visual materials such as icons, sounds, and menus can be replaced with local words or signs and the discussion tool does not have to adhere to a strict structural format, but instead offer in an innovative way that may not necessarily follow a logical thread.

In essence, students should be allowed to have inputs on the structure and format of e-learning as much as possible. Similarly, the social environment in which learning takes place contributes to the students' motivation to learn. The choice of communication media represents another area where significant deliberation must be given. For example, while videoconferencing provides more cues and offers participants opportunities to see other learners (through synchronous interaction), it is more difficult to implement in contexts where high speed broadband access are not available. At the same time, videoconferencing activities have been found to reduce active participation. Video conferencing has a tendency to be more formal than the classroom because interactions are stifled, and students are more reluctant to ask questions. Mailing lists or bulletin boards, on the other hand, offer a low bandwidth alternative but are difficult to set up for synchronous interaction, and are considered lacking in a "personal feel," which may reduce participation level. The choice and selection of the technology medium ought to be done with significant consideration for different cultures.

\section{Case Study: NTI Facing Cultural Challenges}

To face the cultural challenges, we need to have two approaches. The first is to be able to use already existing e-learning courses. In that case, the idea proposed in [10] of using learners annotations to edit learning content frequently can be applied. Annotations can be questions, ambiguities and summarizations. Those annotations could be available with updated courses and categorized based on the country of the person that has contributed in doing them in order to help a new learner to understand the content in a better way. The second approach is to develop new courses. Behind every e-learning course idea created by NTI, the development team has a strategic process that drives efficiency and enables delivering exceptional quality in a short time frame. NTI's methodology accurately defines learning objectives to ensure the effectiveness of the content and design. One of the main objectives is to face the learner's cultural challenges. This aims to developing content which: meets the needs of the learner, is cost effective, has high impact on learner retention, progression and achievement, and relevant to the syllabus. Section A is concerned with cultural challenges assessment, whereas section B illustrates NTI's strategy in facing the cultural challenges.

\section{A. Cultural Challenges Assessment}

The first step before developing any e-learning course is to consider the cultural challenges. Amongst these we can mention: The type of content, pedagogical approaches, instructional media, ..etc.

To assess the cultural challenges we start by posing the following questions [11]:

- Who has access to education?

- Who has access to technology?

- How are students taught?

- What's the role of the instructor?

- What educational resources are available?

- What is 'cheating'?

- How do students prefer to learn?

- How are instructors or professors regarded by students?

- What are the language challenges?

- What learning technologies are available, or not?

- How important are promptness and schedules?

- In what language does education take place?

- What is the motivation to succeed in university?

- What types of activities do learners prefer reading, role playing?

This step is generally followed by finding and examining the required adaptation, Identify cultural adaptation strategies and isolating the minimum elements that need adaptation.

\section{B. NTI's Strategy to Face Cultural Challenges}

This section presents the different directions that constitute NTI's strategy in facing cultural challenges. These directions are the technology solution, and language solution.

\section{1) Technology Solution}

While the needs of organizations and e-learning content providers are essential, the needs of end users (i.e., cultural perspectives and learning styles) must be taken into consideration in the design and development of the technology. E-learning as in any learning is doomed to fail when it fails to focus on learners. Unavailable or high Internet access charges often hinder students from accessing e-learning curricula outside class. Therefore, in NTI, developers take into consideration access to infrastructure and costs. During the content development, videos and images that require a high speed internet are avoided. To allow students to interact with others and with the instructor such as to offer a class like environment, NTI uses the Power-Edu software. The Power-Edu is an online education and video conferencing tool at a time, in other words, it is another multimedia textbook authoring tool and it is also used to perform real time online lectures. The real time online lecture has various real time session options for example, there are two modes: lecture mode and meeting mode, voice encoding options and different video resolution options. A snap shot from a student's discussion is shown in Figure 1. In order to provide an interactive multimedia environment, which is suitable to our Egyptian learning culture that stresses on the importance of interaction between the instructor and students, the NTI's system includes two dream labs. As shown in Figure 2, 


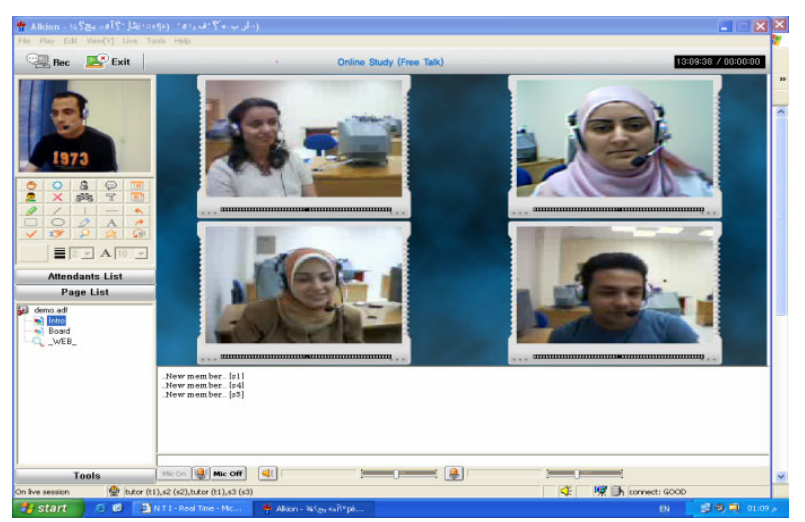

Figure 1. Snap shot of the power-Edu video conferencing tool

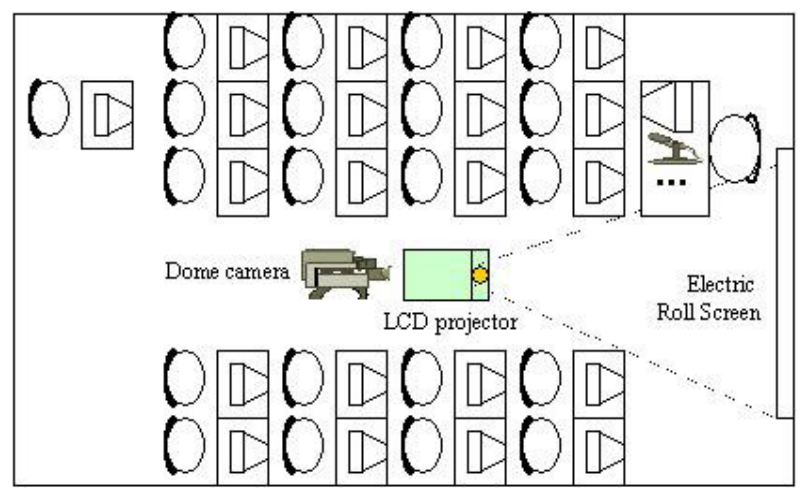

Figure 2. Dream lab top view at NTI

each dream lab is equipped with a dome camera a controller set-up for class animation capturing, an LCD projector, an electric roll screen, an interactive pen display, and an editing system. All the class equipments are connected through a local area network. These labs help the instructors to better guide the students during the class, and using those labs provides a support group where learners can attempt to discuss or resolve complex problems Therefore, the more readily available the user support, the easier a user can figure-out the technology and help other students in doing the same.

\section{2) Language Solution}

As discussed before, the foreign languages represent a barrier for students in understanding the course. Current best practice appears to be represented by the process currently referred to as "localization." This generally consists of two stages[3] :

1. Write (or re-write) content using very basic language (almost always English); avoid idiomatic expressions and any dual meaning or ambiguity; concentrate on communicating at a most functional level.

2. Translate and make minor changes to examples and context to make it suitable to the student's environment.

Most of the NTI target students are used to hear their course explanation in their native Arabic language, while studying the technical words in English. This helps them to better understand the courses. On the other hand having the technical expressions in English is very important since it qualifies the students to work in the market, where English technical expressions are used, and to work in multinational companies as well. Therefore, courses completely taught in Arabic are useless since students will not be able to even work in the local market. NTI has experi- ence in making specialized courses written in English, with options to have the narrations either in English or in Arabic. Hence, the NTI courses meet the students' linguistic needs in a very easy and clear way; in addition they are qualified to work anywhere.

\section{CONCLUSIONS AND FUtURE DiRECTIONS}

In this paper, we focused on the cultural issues related to e-learning. Amongst these issues was the cultural influence, the dimensions of cultural variability. Cultural challenges like language, technology and learning environment and the choice of media were also explained. Finally a case study was presented; it focused on the challenges assessment and strategy followed by NTI in order to face cultural challenges. As NTI has always had a role in training and qualifying graduates in the Arab and African Regions, we plan to have courses specialized for each group of countries having the same culture. We shall start by converting most of the courses offered by NTI to have their narration in Arabic while still pronouncing the technical words in English. In addition, we plan to have some narration in French as well for the Arab countries that use the French language.

\section{REFERENCES}

[1] N. Van Dam, and F. Rogers, “ E-Learning cultures around the world: Make your globalized strategy transparent," Elearning, May 2002, pp. 28-33.

[2] F. Lahwal, and M., Ajlan Al-Ajlan, "Framework of Dynamic Elearning Environment for Interactive Multimedia," niss, pp.105108, 2009 International Conference on New Trends in Information and Service Science, 2009. doi:10.1109/NISS.2009.153

[3] http://www.linezine.com/7.2/articles/pdamca.htm.

[4] A. Joel Mbendera, .C. Kanjo, and L. Sun, "Towards Development of Personalised Knowledge Construction Model for e-Learning," elml, pp.29-35, 2010 Second International Conference on Mobile, Hybrid, and On-Line Learning, 2010. doi:10.1109/eLmL.2010.28

[5] A. Edmundson, Globalized e-learning cultural challenges, Published by Idea Group Inc (IGI), 2007.

[6] A. Edmundson, "Decreasing Cultural Disparity in Educational ICTs:Tools and Recommendations", Turkish Online Journal of Distance Education-TOJDE July 2003 ISSN 1302-6488 Vol. 4 Number:3.

[7] G. Hofstede, Culture's consequences, Beverly Hills, Ca: Sage, (1980).

[8] G. Hofstede, and M. Bond, "Hofstede's Culture Dimensions: An Independent Validation using Rokeach's Value Survey", Journal of Cross-Cultural Psychology, Vol. 15, No. 4, 1984, pp.417-433. doi:10.1177/0022002184015004003

[9] P. Dunn, \& A. Marinetti, "Cultural adaptation: necessity for global e-learning”, Retrieved May 4 2005, from http://www.linezine.com.

[10] A.Kardan, and F. Noorbehbahani, "Using Learners' Annotations to Produce Feedbacks for Selecting and Editing Learning Contents in e-Learning Systems," itng, pp.1128-1133, 2009 Sixth International Conference on Information Technology: New Generations, 2009

[11] A. Edmundson, "Offshore e-Learning: Cultural Challenges, Opportunities, and Solutions," ASTD 2008 International Conference \& Exposition, June 2008.

\section{AUTHORS}

M. A. Azer is with the National Telecommunication Institute, Cairo, Egypt. (e-mail: marazer@ nti.sci.eg).

A. M. El-Sherbini is the director of the National Telecommunication Institute. He is also the assistant of the minister of Communication and Information Technology of Egypt (e-mail: sherbini@mcit.gov.eg).

Submitted October $4^{\text {th }}, 2010$. Published as resubmitted by the authors March $1^{\text {st }}, 2011$. 